\title{
Assessing Awareness and Utilization of Knowledge of Ecosystem Health of Different Communities and Organization in Lake Naivasha Basin Using Stakeholder Analysis
}

\author{
Onyango G.O ${ }^{1}$ Prof. Wegulo F. N. ${ }^{2}$ \\ ${ }^{I}$ (Department of Environment, Egerton University Kenya) \\ ${ }^{2}$ (Department of Geography, Egerton University Kenya)
}

\begin{abstract}
Lake Naivasha is one of the fresh water lakes in the Kenyan Rift Valley. The population within the Lake basin has experienced rapid growth, which has placed enormous strain on the ecosystems within/around it. Critical is over abstraction of underground water by the various flower growing farms, and pollution arising from disposal of both the untreated sewerage and chemicals used in the flower farms. All these effects have potential to adversely affect the already fragile ecosystem, and the general population. Several research activities have already been conducted, with others underway, to capture and document the ecosystem health status within the Lake Basin. In spite of these efforts, ecosystem health degradation is continuing at an alarming rate. Clearly a gap exists between researches conducted on one hand and utilization of the findings for sustainable development on the other hand. The study therefore sought to contribute towards sustainable management of resources in the Lake Naivasha Basin through encouraging appropriate access and utilization of ecosystem health research findings information by the various stakeholders. Specifically the objective was to carry out stakeholder analysis on knowledge of stakeholders on ecosystem health. A sample of 304 was arrived by using sample calculator using sample frame of the households of primary stakeholders (flower farm workers, pastoralists, fishing community). Questionnaires, interview schedules and focus group discussions were used to collect the data. Results from the analysis show that in spite of many research studies already conducted the research findings has not been able to reach the various stakeholders to utilize the information due to lack of accessibility, language used is technical, level of education is low. Most of the respondents felt that for them to utilize the research information, stakeholder advisory board needed to be formed to manage the information, the research information need to be simplified and written in Kiswahili language which most people can understand and should be disseminated by radio. This will lead to the Lake utilized in a sustainable way.
\end{abstract}

Keywords: Utilization, Awareness, Research findings, Stakeholders

\section{Introduction}

Lake Naivasha is a fresh water lake located within the Kenyan section of the Great Rift Valley. The lake derives its name from Naiposha, a Maasai word meaning "rough water" in reference to sudden storms which commonly occur in the area. The lake has a surface area of $139 \mathrm{~km}^{2}$, and is surrounded by a swamp which covers an area of $64 \mathrm{~km}^{2}$. It is situated at an altitude of 1884 meter (6180ft) above sea level. The lake has an average depth of 6 meters (20ft) with the Crescent Island as the deepest end, at a maximum depth of 30 meters (100ft) (Francesca et al., 2011)

The Lake provides a habitat to a variety of wildlife, with over 400 different species of birds that include; water fowls, fowls, penguins, flamingos, falcons, eagles, hawks, cranes, doves, parrots, cuckoos, owls, kingfishers, woodpeckers, mouse birds and many others (Francis, 2010). A sizeable population of hippos also exists within the lake. Two smaller Lakes are found within the vicinity of Lake Naivasha, namely Oloiden and Sonachi. The latter lake shore is known for its population of European immigrants and settlers.

Lake Naivasha area plays an important role in national development. It is one of the major contributors of Kenya's export of approximately 134,000 tonnes of cut flower, fresh fruits and vegetables (HCDA, 2007). In 2006 , the proportion for cut flower increased by $40 \%$ compared to fruits and vegetables. At that time 49,000 tonnes of cut flower valued at US\$112 million were exported (Kenya Flower Council, 2006). Furthermore, 15\% of Kenya's electricity power generation is from Olkaria geothermal station and several tourist attractions sites are located within Lake Naivasha Basin (Mireri, 2005).

Since Kenya's independence in 1963, Lake Naivasha basin has undergone rapid land use transformations characterized by commercial ranching, and small-scale agricultural activities. In the last two decades, the area has become an expansive commercial flower-growing zone, largely by foreign companies. This has increased demand for the scarce ecosystem resources and services, especially water and land. The results have been significant water abstraction from both the Lake and underground sources by the floriculture industry, a major ecosystem health problem. In the absence of any meaningful controls e.g. metering, water is 
"free for all". This is not healthy for the ecosystem and the population living there. Accelerated water abstraction through direct and indirect methods poses immediate and long-terms risks to the ecosystem and the existence of the Lake. The demand on water for flower growing is compounded by the needs of the fast growing population. What is not immediately clear is whether or not the water users such as flower growing companies are aware of the ecosystem consequences of their actions. Or could it be that they lack essential research based information on the basis of which they could make more informed decisions on management of the basin's resources?

Other harmful practices in the basin include rampant discharge of raw sewage into the Lake, resulting in eutrophication and high demand on available oxygen in the Lake (Mireri, 2005). A related problem is rampant use of pesticides by flower farms and chemical fertilizers among small scale farmers in the upper catchment area of the Aberdares. It is alleged that some flower farmers are using unacceptable chemicals such as organo-chlorine pesticides and some of these pesticides have been detected in Lake Naivasha (Gitahi et al., 2002). Through biomagnifications, such chemicals could affect bird species at the top of the food chain. These activities have the potential to adversely affect the health status of a growing number of people and other life systems within the Lake Naivasha Basin (Lake Naivasha Management Plan, 2004). Evidence of the emerging ecosystem health degradation is the decline in the number of bird and fish species found on the Lake Naivasha (Abiya, 1996).

The quantity of data and research on Lake Naivasha and its drainage is overwhelming (Robert et al., 2006). The number of researches done to generate knowledge is 182 (Personal communication Charlie Trick). The key thematic areas which have been researched on are; aquatic plants, parasites of fish, different species of fish, water budget, invertebrates, human activities, pollutants in the Lake Naivasha and climate change effect on Lake Naivasha, just to mention a few. Out of the 182 researches done, of interest were; 21 researches covered pollution of the Lake Naivasha, 28 researches covered macro invertebrates/nutrients/breeding/diet, 32 researches covered different species of fish/distribution/weight-length/breeding/diet, 10 researches covered impact of human activities on Lake Naivasha, 8 covered climate change impact on Lake Naivasha, 15 researches covered different species of birds/breeding/feeding and 3 researches covered water budget. These researches are important to people living around Lake Naivasha basin depending on their socioeconomic activities. Going by 182 researches done, none addressed how best to utilize the research information generated there.

Despite all these researches, ecosystem health degradation is still a threat to Lake Naivasha basin. The major challenge might be accessibility since most of the findings are published in international journals not accessible to local resource users. The other problem might be lack of resource centre where various researches can be stored for easy access by local resource users. After considering the wealth of ecosystem health information available, it would appear that further research may not be the main priority but dissemination and utilization of existing information for sustainable management of Lake Naivasha Basin. There are many players with different, and many times, competing needs and influence (stakeholders) within Lake Naivasha Basin. These have disruptive effects on the water balance, quality of water and air, sustainability of ecosystem including fish, vegetation, birds etc (Aberdares) (LNROA, 2000). However, it is not quite clear how each of these stakeholders can contribute towards sustainable management of the Lake's basin. It was in view of this that stakeholder analysis was carried out to understand the main players in Lake Naivasha basin, and their influence and role in ensuring sustainable use of Lake Naivasha.

\subsection{Statement of the Problem}

Lake Naivasha is an important ecosystem health because it supports a variety of socio-economic activities. As a result of these activities, the population in the area has been increasing rapidly, and has posed a number of challenges to sustainable use of the ecosystem due to over abstraction of water, loss of biodiversity and pollution of the Lake. Review of literature suggests that several empirical studies have so far been conducted and related research findings made known to the researchers but not the resource users. However, it is apparent that the study area continues to experience ecosystem health related problems due to the non utilization of research findings by the resources users. This paradoxical situation raised a fundamental question as to what might be the reason for the mismatch between available ecosystem health research findings and continuing environmental degradation. It was against the recognition of this gap that a stakeholder analysis was carried out to understand the main players in Lake Naivasha basin and their influence and role in ensuring sustainable use of Lake Naivasha.

\section{Literature Review}

With the current ecosystem health challenges facing Lake Naivasha Basin, there is a need to determine ecosystem health research information needs based on the current and existing policies in order to come up with ways in which the various ecosystem health research information can be compiled, disseminated and utilized. According to (Michael et al., 2007) factors influencing the utilization of research findings by all stakeholders include access to information, relevance of the research, use of the research perceived as a time consuming 
process, trust in the research, authority of those who present their views, competency in research methods, and priority of research in policy process and accountability.(Closset al., 1994) suggested that utilizing research findings was a highly complex task, requiring a positive attitude towards research. (McGuire, 1990) states that the issue of utilizing research findings in practice was more than simply viewing difficulties of using it, as the failure of individuals to respond to new knowledge, or to innovations also counts. In their study, (Goode et al., 1992), revealed that the organization aspect on research management and communication process contributed to research findings' utilization. Thus, utilization of research findings should not be seen as a separate entity which is performed independently of other duties (Roger, 1994). The issue spans the planning phase of research to implementation and actual utilization, including possible implications. Successful application of research findings, therefore, depends upon the interest and commitment of both researcher and user (stakeholder) and cannot be achieved in isolation (Bircumshaw, 1990). The research has established the challenges which affect the utilization of research findings by the stakeholders concern and the possible way to improve the utilization of the information.

According to research done by (Bond, 2002), a number of policy and profession-led initiatives have moved therapy toward an evident-based culture. Accessing information, particularly research-based findings, is fundamental to the concept of evidence-based practice. Little is known about the extent to which therapists are searching actively for research information, or what they perceive as barriers to accessing research information or implementing research into practice. A mixed method design was used to gather quantitative $(\mathrm{n}=127)$ and qualitative $(n=77)$ data from a population of Occupational, Physiotherapy and Speech and Language therapist employed in rural Community Trusts. The result indicated that only a small proportion of therapy professional in the study adopted a proactive strategy for identifying, retrieving and utilizing research information. Individual, organizational and cultural issues were identified that were perceived to be barrier to the process of accessing and interpreting research findings. Individuals were judged to have different degree of research receptivity. This concept incorporates dimension of self-efficacy with respect and personal impressions of research that combine to encourage or undermine an individual's engagement with research and its products. In conclusion, for better research receptivity, the approach was to increase allocation of resources, provision of educational activity and dissemination of research information that accommodates the research attitudes and skills of individual therapy professionals. Veeramah (2007) assessed the impact of research education on the attitudes toward research and use of research findings in a sample of graduate nurses and midwifery. His research examined how nurse and midwifery teachers could work collaboratively with clinical staff to enhance their use of research evidence to inform their practice. The main barriers to research utilization and strategies that could facilitate the use of research findings in nursing and midwifery were also explored.

The project was carried out in three phases and aspects of theory of diffusion of innovation and theory of planned behaviour were used as the theoretical framework to inform data collection. For the first phase, a cross-sectional survey using a self-completed postal questionnaire was sent to 340 graduates. A response rate of $56 \%$ was obtained. A large number stated that following graduation, their search and critical appraisal skills had improved, expressed positive attitude towards research and reported using research findings in practice. The second phase explored further the extent of research utilization. Semi-structured interviews were conducted with 10 respondents from a range of specialties. All participants claimed that they used research findings to a large extent and provided examples to support their answers. The third phase, using a structured questionnaire, explored strategies that nurse and midwifery teachers could use to help nurses and midwives to improve their use of research findings. A total of 40 teachers and 62 clinical managers took part. The result was effective strategies were identified including enabling clinical staff to access and critique research papers; run research workshops on site; set up journal club or research interest groups and undertake joint research projects.

\section{Methodology}

The study was conducted in Hell's Gate Location, which is located in Rift Valley Province of Kenya (Figure 1). The population in the area surrounding the lake has rapidly grown from 7000 in 1969 to about 300,000 by 2007 (Food and Water Watch, 2008). It is estimated that the population will be close to one million by 2025 , in consonance with sub-Saharan estimated urban population growth rate of $6.9 \%$ per annum as compared to $3.1 \%$ of the total population of the region (Ayenew et al., 2007). Such growth rate is likely to have serious challenges to sustainable use of Lake Naivasha Basin. 


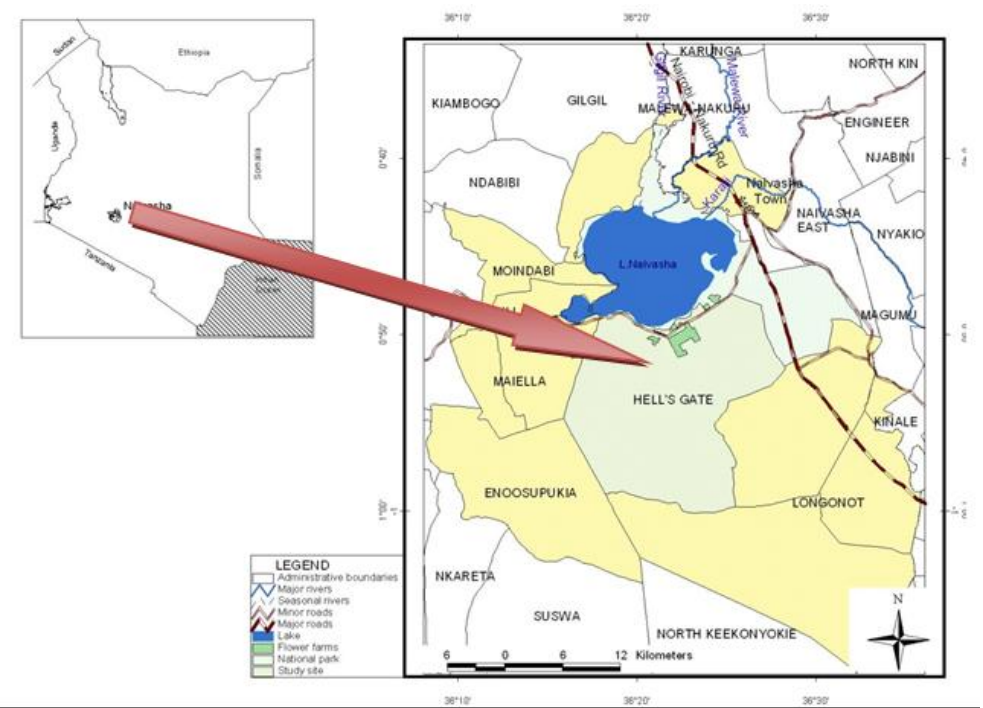

Figure 1: Map of Kenya and Naivasha Basin showing the Study Area (Source Cartographer Egerton University)

This study employed a social survey research design based on qualitative and quantitative approaches to collect the relevant data from the study areas (Hell's Gate Location). The study targeted individual farmers, pastoralists, flower firm workers housed and not housed within Flower farms company sites, fish monger and business people. The sampling frame included a list of pastoralist, indigenous farmers, and flower firm workers obtained from Hell's Gate Location Chief's Office. A total of 304 respondents were targeted by the study. Questionnaires, interview schedules and focus group discussions were used to collect the data. Both quantitative and qualitative data analysis techniques were used to analyze the data. The quantitative data were analyzed using descriptive statistics while thematic analysis technique was used to analyze the qualitative data collected through focus group discussions and interviews.

\section{Findings of the Study}

The objective of this study focused on assessing the knowledge of various stakeholders on the status of ecosystem health within the Lake Naivasha basin. Stakeholder meeting was held in Naivasha on $9^{\text {th }}$ December 2010 to establish among other things; perception, knowledge, accessibility to and utilization of research findings for Lake Naivasha sustainability. Different communities and organizations were invited to participate in the stakeholder's workshop, where five groups were established. Stakeholder group 1 identified users of Lake Naivasha, threats, dependants and legal jurisdiction. Stakeholder group 2 identified people knowledgeable about Lake Naivasha and challenges facing people leaving around Lake Naivasha. Stakeholder group 3 discussed and identified decision makers regarding the use of Lake Naivasha resources. Stakeholder group 4 discussed and listed stakeholders who supported the Lake Naivasha sustainability in regard to use of its resources. It focused on those who will support it and not support it. Those who do not support, how can they be won to support its sustainability? Stakeholder group 5 identified methods of sharing of research information generated. The discussion centered on important stakeholders in sharing ecosystem health research information generated, types of ecosystem health research information to share, in what form the information is needed presented and language.

Stakeholder group one focused on establishing the users of resources within Lake Naivasha Basin and the practices which threaten the existence of the Lake's resources. From the deliberation, it emerged that the users of the Lake were fisher men, flower farmers, poachers, hoteliers, wild animals and churches. The practices which threatened the existence of the Lake included: discharging of sewage into the Lake, abstraction of water by flower farmers for irrigation, environmental degradation caused by pastoralists who take their animals to drink from Lake Naivasha via the few corridors available and that poachers and communities living around the lake use the natural resources available as wildlife and cutting down trees for charcoal burning. On the other hand, the study established that Lake Naivasha also acts as a source of income to the government through taxing the fishermen, flower farmers and tourists. From the deliberation, all stakeholders felt that all users of Lake Naivasha and its natural resources have a moral obligation to protect the Lake starting with Provincial administration, NEMA, KWS, Municipal Council of Naivasha, local population, flower farms and through international treaties such as RAMSAR conventions. Stakeholder group two, focused on assessing the knowledge of the communities around the Lake on the health of the ecosystem. From the discussion, it emerged that people/groups/organizations knowledgeable about Lake Naivasha and its natural resources included; WRMA, Fisheries, BMU, LNGG, small and large scale farmers, Naivasha Municipal Council, Naivasha Water 
and Sewage Company, Public health and sanitation, Pastoralists, KENGEN, KWS and KFS.The depth and breadth of knowledge varied from group to group and depended on how the resources were used. Among the stakeholders, pastoralists were more affected by drought and famines, BMU were more affected by natural calamities which resulted from decline in Lake Naivasha water level. In addition, pastoralists were more affected by global climate change, accessibility to Lake Corridors, raw sewage discharged into the Lake, siltation and chemical discharge, conflicting interest among the stakeholders and human wildlife conflict. It also emerged that a number of ecosystem health research initiatives and projects had been done around the lake without fully involving stakeholders, unclear implementation strategies, no integrated management approach and ignorance. Finally, it emerged through stakeholders meeting ecosystem health research findings generated were not sufficiently shared for sustainable management of the Lake Naivasha resources.

Stakeholder group three, identified decision makers on utilization of Lake Naivasha resources.It emerged that the decision makers were WRUA in the upper and lower catchments of LNB, Flower farmers, Fishing communities, pastoralists, the tourist industry, CFA, Government institutions, political groups, Municipal Council of Naivasha and NGOs. It was also revealed that influential people/groups in the project area were the beneficiaries, i.e. NEMA, Fishing communities, Pastoralists and farming communities around the Lake. Stakeholder group four focused on finding out those who will support the ecosystem health sustainability so long as they are involved. These stakeholders included: the Municipal Council, Flower farms, hoteliers, pastoralists, KWS, Water Companies, WRUA, CFA, relevant ministries, NEMA, Provincial Administration, small scale farmers, KENGEN, the business fraternity, land owners, learning institutions, development partners, flower buyers, political groups, Public health ministries, the Media and religion groups. From the deliberations, some organizations which had been involved in ecosystem health research included: the media, government institutions, research institutions, resource users and international universities. Local people and the general public had not been effectively and inclusively involved in ecosystem health research. It was further revealed from deliberation that the National Council for Science and Technology had abandoned their responsibilities of giving licenses to researchers and were not aware of the ecosystem health researches which were being carried out around the Lake region. National Council for Science and Technology did not have central data centre for accessing ecosystem health research information by the public. It was finally found that relevant government authorities had not been fully involved in carrying out enforcement and compliance e.g. failure to stop bad practices around the Lake.

Stakeholder group five deliberated on sharing of knowledge of ecosystem health research information. It was established that the stakeholders who were involved in sharing of knowledge of ecosystem health research findings included: local communities, WRUA, Government line ministries, local authorities, hotels, Media, Kengen, Development partners, policy makers and international conventions. Some of the ecosystem health research information knowledge shared included: global climate change, environmental degradation, waste management, water budget, dumping sites and waste, ecosystem health, water quality and sustainable use of natural resources. Information knowledge generated was shared to educate stakeholders on practices which degrade the environment around and in the Lake, interventions for climate changes, empowerment, improvement of the health of the people and finally to spur economic growth when using resources in a sustainable way. For effective sharing of ecosystem health research information generated, the group was of the opinion that research information should be deposited in a resource centre where people can consult to get information they want and the information generated used to develop short documentaries. The group was also of the opinion that the information generated should be translated into Kiswahili which is a national language and which can be understood by the majority of all the stakeholders in Naivasha. Some stakeholders were of the opinion that the research information should be translated into vernacular and sign language for those who are deaf. Majority of the group members felt that the best mode of dissemination of research findings was through Radio since that is what most residents of Naivasha can afford. Electronic media, posters, meetings such as Baraza, pamphlets, drama, music and art were also recommended to be used to disseminate the information generated.

From the deliberations of the stakeholder groups, it became clear that, Lake Naivasha had many users (stakeholders) who pose many threats to its existence. Good will existed for the support of the utilization of the Lake Naivasha Basin in a sustainable way, since many users faced same or different challenges on accessing, level of language used and lack of resource centre for utilization of research findings information generated. This relates closely to (Closs et al., 1994) suggesting that utilizing research findings was a highly complex task, requiring a positive attitude towards research for its success during the time of implementation. Grid was used to categorize the entire stakeholders within Lake Naivasha Basin to show how their power and interest is at play. From the grid the stakeholders were categorized based on power and interest (Figure 2). The stakeholders with more power and less interest needed to be managed very closely for the success of the sustainability of the LNB. In this regard they were the stakeholders with more resources and were involved in flower farming, extracted more water from the Lake and probably were also polluting the Lake directly or indirectly. They also had the 
capacity to sabotage the success of the sustainability of LNB. The group with high level of interest and more power comprised government officials who have influence in mobilization of people to support the sustainability of LNB and at the same time they have influence in advising the government with regard with policy issues. These groups needed to be involved in every stage of the sustainability of LNB since they will be used to regulate the socioeconomic activities within Lake Naivasha. The group with high interest and less influence needed to be informed when the sustainability of LNB is completed. This is due to the fact that they are the most vulnerable group and depend on the Lake Naivasha resource directly. Any information reaching them can trigger social tensions and need to be managed very carefully.

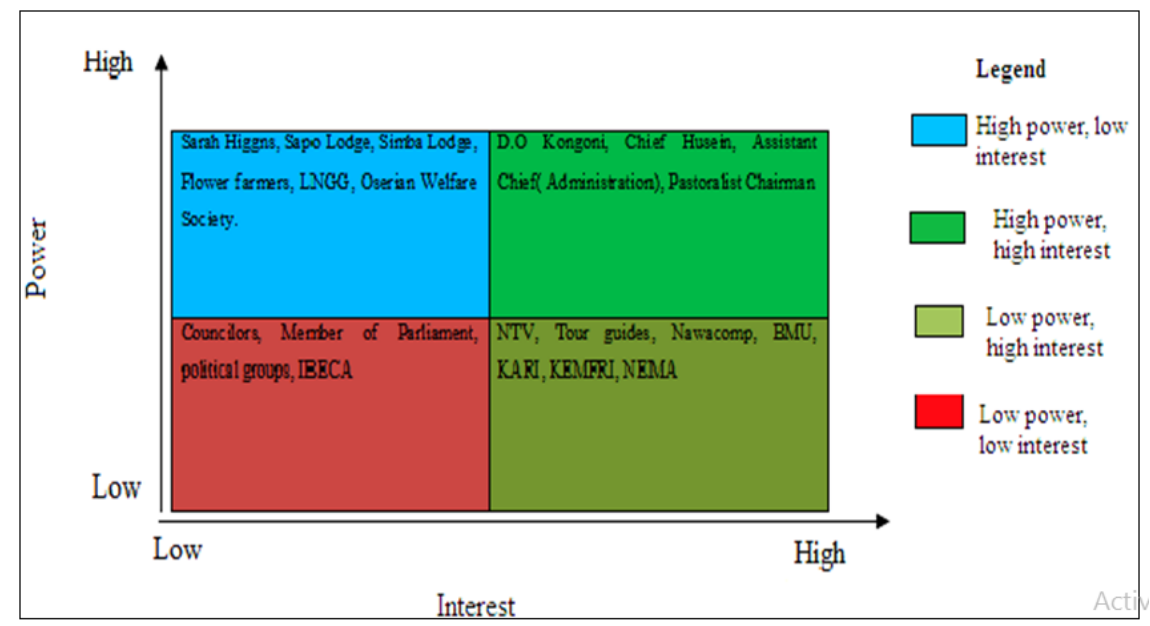

Figure 2: Stakeholder power-interest matrix (Modified from Charlotte and Hans, 2007)

From the stakeholders meeting, it was established that there was need to form Stakeholders Advisory Board ( $\mathrm{SAB}$ ) to manage sharing of the ecosystem health research information and the formation of resource centre with a view to sustainable use the LNB resources. It was suggested that SAB should comprise 15 members each drawn from WRUA, Pastoralist, Lake Naivasha Grower Group, Small scale farmers, C.S.O forum, Eco-tourism, BMU, CFA, LNRA, Naivasha municipal council, Business community, other local authorities, youth groups, women representatives and government ministries. Involvement of stakeholders in LNB compares very closely with study done (Kostas and Kostas, 2011) where all the stakeholders were involved in the management of the Greek Municipality success which was achieved through consultation, deliberations, co-operation with important organizations and the use of international best practices. Issues brought on board were social, economic and cultural. The benefit has been good economic growth, productivity, competitiveness, social inclusion and sustainable development. From the stakeholder's meeting the issue of sustainability of the Lake Naivasha Basin came out strongly through the utilization of research findings generated there.

\subsection{Summary of Findings}

From the findings of the study, it was noted that Lake Naivasha Basin is composed of many type of stakeholders with varying level of resources and power. These stakeholders include WRMA, Fisheries, BMU, LNGG, Municipal Council of Naivasha, Naivasha Water and Sewage Company, flower farmers, poachers, hoteliers, wildlife, local population and churches. They all use the lake's resource in different ways to satisfy their needs. The stakeholders are knowledgeable about ecosystem health of Lake Naivasha. However, the depth and breadth of this knowledge varies from group to group and depend on how the resource is used.

\subsection{Conclusions}

The study concluded that Lake Naivasha Basin is composed of many type of stakeholders with varying level of resources and power use the lake's resource to satisfy their needs. The stakeholders were found to be knowledgeable about ecosystem health of Lake Naivasha, however, the depth and breadth of this knowledge varies from group to group and depends on how the resource is used.Many research initiatives have been undertaken with limited involvement of all the stakeholders in sharing of ecosystem health research findings. In this regard there is need to share the research findings to empower all the stakeholders for sustainable management of Lake Naivasha Basin. Factors contributing to the utilization of ecosystem health research findings include; lack of awareness of the existence of ecosystem health research finding information, lack of resource centre, lack of resource personnel, use of technical language, inadequate education, and inadequate access to research findings among the stakeholders. 


\subsection{Recommendation}

Lake Naivasha Basin is characterized by many socio-economic activities that are undertaken without proper adherence to principle of sustainable development. This result in unsustainable utilization of natural resources despite many research information generated there. To address these challenges, there is need to establish approaches on how to use many ecosystem health research information generated in order to reverse unsustainable utilization of natural resources in LNB.

\section{References}

[1]. Abiya, I. O., (1996). Lake and Reservoirs: Research and Management.Towards sustainable Utilization of Lake Naivasha Kenya 2: 231-242.

[2]. Ayenew,Y. A., Wurziger, M., Tegegne, A., and Zollitsch, W., (2007). Urban and Peri- urban Farming Systems and Utilization of the Natural Resources in the North Ethiopian Highlands, University of Kassel-Witzenhausen and University of Göttingen.

[3]. Charlott, B., Hans, H., (2007). Approaching reality: Comparing Stakeholder analysis and Cultural theory in the context of natural resources management. Tema Institute Linkoping University 83 Linkoping Sweden.

[4]. Closs, S. J., Cheater, F. M., (1994). Utilization of Nursing Research: culture, interest and support. Journal of Advanced Nursing 19(4) :762-773.

[5]. Francesca, G., Robert, J.B., Kenneth, M. M., Nic. P., Jonathan, G., Elena, T., David, M.H., (2011). A review of allo diversity in Lake Naivasha Kenya: Developing conservation action to protect East Africa lakes from the negative impact of alien species. Biological conservation 144(11): 2585-2596

[6]. Francis, M., (2010). The influence of geographic and morphometric factors on the distribution of water birds species in small high altitudes tropical man made reservoirs, central rift valley Kenya. Africa journal of ecology.48(3):676-690.

[7]. Food and Water Watch., (2008). Lake Naivasha withering under the Assault of International Flower Vendors. Council of Canadian.

[8]. Gitahi, S.M., Harper, D.M., Muchiri, S. M., Tole, P.M., Ng'anga, R.M., (2002). “Organochlorine and Organophosphorus pesticide concentration in water, sediments, and selected organisms in Lake Naivasha (Kenya).” Hydrobiologia 488 (1-3):123-128

[9]. HCDA., (2007). Horticultural Crop Development Authority report. Government Printing press Kenya

[10]. Kostas, E., Kostas, M., (2011). Formulating integrated knowledge city development strategies: The Know C is 2.0 methodology. Knowledge management research and practice 9,172-184

[11]. LNROA., (2000). A three phase environmental impact study of recent developments around Lake Naivasha. John Golden Association. Kenya

[12]. LNROA., (2004).The Lake Naivasha Management Plan. John Golden Association. Kenya

[13]. Mireri, C., (2005). Challenges facing the conservation of Lake Naivasha Kenya, Kenyatta University Printing Press Nairobi Kenya.

[14]. Robert, B., Eric, O.O., Sarah, H., (2006). Lake Naivasha Experience and Lesson Learned Briefs. Lake Naivasha Riparian Association. 